\title{
Small RNA Function in Plants: From Chromatin to the Next Generation
}

\author{
Jean-Sébastien Parent, ${ }^{1,2,3}$ Filipe Borges, ${ }^{1,2,4}$ Atsushi Shimada, ${ }^{1,2}$ \\ and Robert A. Martienssen 1,2 \\ ${ }^{1}$ Howard Hughes Medical Institute, Cold Spring Harbor, New York 11724 \\ ${ }^{2}$ Cold Spring Harbor Laboratory, Cold Spring Harbor, New York 11724 \\ Correspondence: martiens@cshl.edu
}

\begin{abstract}
Small RNA molecules can target a particular virus, gene, or transposable element (TE) with a high degree of specificity. Their ability to move from cell to cell and recognize targets in trans also allows building networks capable of regulating a large number of related targets at once. In the case of epigenetic silencing, small RNA may use the widespread distribution of TEs in eukaryotic genomes to coordinate many loci across developmental and generational time. Here, we discuss the intriguing role of plant small RNA in targeting transposons and repeats in pollen and seeds. Epigenetic reprogramming in the germline and early seed development provides a mechanism to control genome dosage, imprinted gene expression, and incompatible hybridizations via the "triploid block."
\end{abstract}

Epigenetic phenomena have long been recognized and even harnessed in plants. Examples include early studies from Barbara McClintock on how transposons act as controlling elements through the production of a "repressor substance" (McClintock 1961), imprinting and the nonreciprocal fate of hyperploid seeds (Blakeslee et al. 1920; Kermicle 1970), transgenerational paramutation (Coe 1966; Chandler 2010), and somaclonal variation (OngAbdullah et al. 2015). It is now widely accepted that small RNA molecules (sRNAs) (21- to 24-nt-long in plants) actively participate in all these phenomena, but how these molecules themselves influence cell fate in subsequent generations remains mysterious (Heard and Martienssen 2014). Exciting recent studies in plants and in other eukaryotes now point to new roles for these small RNAs that are demanding further investigation.

From developmental signaling to virus resistance, sRNAs have many important functions in plant cells, yet the majority of them target repeats and transposable elements (TEs) previously considered largely inert (Borges and Martienssen 2015). Active transposons present the cell with an important challenge given their propensity to copy themselves and "move" within the genome, as well as causing chromosomal instability and thereby necessitating tight control. What makes sRNAs particularly well-suited to silence these elements is their ability to recognize sequence homology in trans. Indeed, host defense against invasive species appears to be a conserved function of sRNAs and associated factors going all the way back to prokaryotes (Swarts et al. 2014). More recent studies have cast a new light on McClintock's early ob- servations in maize, showing that transposons provide an important source of regulatory elements for endogenous gene expression (Chuong et al. 2017). Indeed, the massive expansion of specific transposon families in different eukaryotic genomes provides abundant regulatory opportunities for sRNA-mediated control of gene expression at a genome-wide scale. Here, we summarize recent findings on how plant sRNAs regulate cell fate and transgenerational inheritance of epigenetic states.

\section{GENERATING SMALL RNA MOLECULES}

sRNAs in plants have different sizes owing to a variety of DICER-LIKE (DCL) proteins each specializing in a given size class (Borges and Martienssen 2015). In flowering plants, repeated regions and TEs typically produce small-interfering RNA molecules (siRNAs) that are 23- to 24-nt-long, although abundant 21-nt and 22-nt siRNAs are also produced in some species or specific developmental contexts and are known as epigenetically activated siRNA (easiRNA) (Nuthikattu et al. 2013; Creasey et al. 2014). easiRNA precursors can be transcribed by the RNA polymerase II (Pol II) or the plant-specific RNA polymerase IV, which shares many subunits with Pol II and is generally required for TE siRNA production. Pol IV generates short transcripts (Blevins et al. 2015; Zhai et al. 2015) that are immediately converted into double-stranded RNA by the RNA DEPENDENT RNA POLYMERASE2 (RDR2), which forms a complex with Pol IV and is required for polymerase activity (Singh et al. 2019).

\footnotetext{
${ }^{3}$ Present address: Ottawa Research and Development Center, Agriculture and Agri-Food Canada, Ottawa, Ontario K1A 0C6, Canada

${ }^{4}$ Present address: Institut Jean-Pierre Bourgin, Institut National de la Recherche Agronomique de Versailles-Grignon, 78026 Versailles Cedex, France

(C) 2019 Parent et al. This article is distributed under the terms of the Creative Commons Attribution License, which permits unrestricted reuse and redistribution provided that the original author and source are credited.
} 
Importantly, the emergence of Pol IV allowed transcription of heterochromatic regions that are refractory to Pol II, thus allowing abundant production of siRNAs from transcriptionally silent transposons and repeats. One important factor required for Pol IV recruitment to a subset of heterochromatic loci is the SAWADEE HOMOEDOMAIN HOMOLOG1 (SHH1) protein, which binds to the dimethylated lysine 9 on histone 3 (H3K9me2) and resembles homeobox transcription factors (Law et al. 2013). Targeting of transcription to heterochromatin also occurs at Piwi-interacting RNA (piRNA) clusters in Drosophila, via the methylated $\mathrm{H} 3 \mathrm{~K} 9$ binding protein Rhino, presumably for much the same reason (Mohn et al. 2014; Yu et al. 2018). More recently, it was shown that the different members of the SWI2/SNF2-type chromatin remodeling protein family CLASSY (CLSY) also assist in Pol IV recruitment at specific targets (Zhou et al. 2018). Although CLSY1 and 2 appear to act together with SHH1, the recruiting partner(s) of CLSY3 and 4 are still unknown.

Paradoxically, RNA polymerase is required for expression, whereas sRNAs are associated with silencing. Perhaps for this reason, there is a constant need for surveillance of Pol II transcripts to intercept potentially problematic transcripts derived from transposons. In Arabidopsis thaliana, Pol II-dependent TE transcripts are rapidly targeted by a variety of endogenous microRNAs (miRNAs) that trigger production of 21- to 22-nt siRNAs via RDR6, DCL2, and DCL4 (Creasey et al. 2014). Interestingly, certain miRNA families in plants evolved to target long terminal repeat (LTR) retrotransposons specifically. Most notably the miR845 family targets retrotransposons at the conserved primer-binding site (PBS) where transfer RNAs (tRNAs) bind to initiate reverse transcription (Borges et al. 2018). Targeting the PBS with small RNA is a common mechanism for transposon control in both mammals and plants, via $3^{\prime}$ fragments of mature tRNA in mammals, and via miRNA derived from rearranged tRNA in plants (Šurbanovski et al. 2016; Schorn et al. 2017). At least in mammals, $3^{\prime} \mathrm{CCA}-\mathrm{tRF}$ are potent inhibitors of retrotransposition and might provide a uniquely sensitive means to monitor transposon activity in eukaryotic genomes (Schorn et al. 2017).

In plants, miRNAs are produced by the enzyme DCL1, whereas secondary siRNAs can be the product of either DCL2, DCL3, or DCL4 (or any combination of the three) working in combination with RDR6 (Borges and Martienssen 2015). Although most sRNAs from TEs are 24 nt in length, there are a few repeated loci in Arabidopsis that generate 21- and 22-nt secondary siRNAs (Panda et al. 2016). These siRNAs resemble easiRNAs, which arise in specific genetic, cellular, and/or temporal contexts and depend on DCL2 and DCL4. For instance, the massive activation of transposons in DEFECTIVE IN DNA METHYLATION1 (DDM1) mutants causes easiRNA accumulation in Arabidopsis, maize, and tomato (Slotkin et al. 2009; Creasey et al. 2014; Corem et al. 2018; Fu et al. 2018). easiRNAs also arise in support cells within gametophytes and in the seed, where TEs are epigenetically reactivated during reprogramming (Slotkin et al.
2009; Calarco et al. 2012; Ibarra et al. 2012). Intriguingly, easiRNAs in pollen depend on a noncanonical pathway involving components of both the siRNA and secondary siRNA pathways in plants, including RNA Pol IV, DCL2, and DCL4 (Borges et al. 2018; Martinez et al. 2018). This is especially interesting as heterochromatin is lost from the vegetative nucleus (VN) (the "nurse cell" in pollen) as well as from the microspore. In seeds the same pathway is required for the biogenesis of DCL4 isoform-dependent siRNAs (disiRNAs). These 21-nt small RNAs depend on a DCL4 isoform found in Arabidopsis and potentially in other Brassicaceae like Capsella rubella, which includes a nuclear localization signal (NLS) and depends on loss of DNA methylation for expression (Pumplin et al. 2016). Loss of DNA methylation and expression of this isoform is found in pollen and in endosperm, consistent with these observations (Pumplin et al. 2016; our unpublished results). A recent study also showed that sRNA molecules of 21, 22, and $24 \mathrm{nt}$ are also dependent on Pol IV in the microspores of Arabidopsis and C. rubella (Fig. 1A) (Wang et al. 2020), indicating that biogenesis of gametophytic easiRNA is conserved at least in Brassicaceae.

Importantly, easiRNAs in pollen accumulate in sperm cells, but arise in the microspore and the VN, suggesting that they might move from cell to cell (Slotkin et al. 2009) (Fig. 1B), together with other small RNAs. This was recently showed in Arabidopsis pollen as transgene small RNA products made by DCL 2 and DCL 4 moved from the $\mathrm{VN}$ to the sperm cells to silence target transcripts (Martínez et al. 2016). One question that remains is whether these molecules diffuse passively or if they are actively transported by a protein factor, such as a member of the ARGONAUTE (AGO) family. Regardless, there is significant potential for sRNAs loaded in sperm cells to be delivered to the egg and central cells and contribute to early embryo and endosperm development (Fig. 1B,C), as has been shown for at least one miRNA (Zhao et al. 2018). One idea is that easiRNAs mediate the transition from cytoplasmic posttranscriptional gene silencing (PTGS) to nuclear transcriptional gene silencing (TGS) during epigenetic reprogramming, to establish or reinforce transgenerational silencing at imprinted loci (Teixeira and Colot 2010; Borges and Martienssen 2015).

\section{REPROGRAMMING CHROMATIN WITH SMALL RNA}

Epigenetic reprogramming refers to the erasure and resetting of epigenetic marks acquired during the life of the parent, and in mammals it occurs in the gametes and in the embryo (Heard and Martienssen 2014). The extent of reprogramming in plants is much less pronounced, and epigenetic inheritance far more common, as the plant germline maintains high levels of DNA methylation during the sporophytic (somatic) to gametophytic (germline) transition (Calarco et al. 2012; Ibarra et al. 2012; Ingouff et al. 2017; Walker et al. 2018). In plants, sRNAs can trigger cytosine methylation $(\mathrm{mC})$ in all sequence contexts ( $\mathrm{CG}, \mathrm{CHG}$, and $\mathrm{CHH}$, where $\mathrm{H}=\mathrm{A}, \mathrm{C}$, or $\mathrm{T}$ ) via RNA- 
A Meiocyte/Microspore

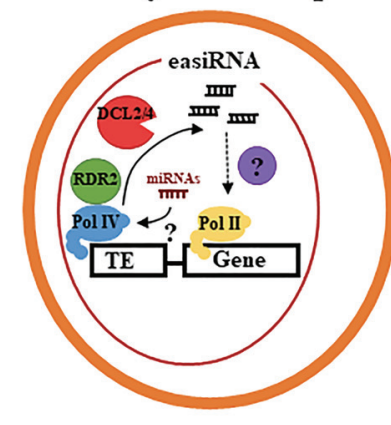

D

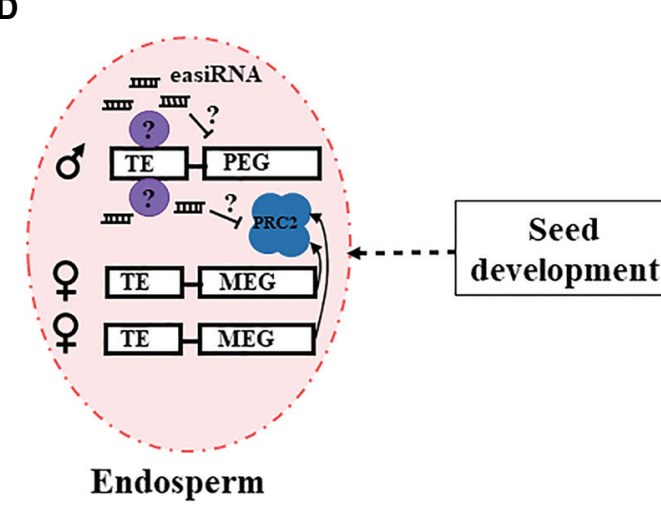

B Pollen
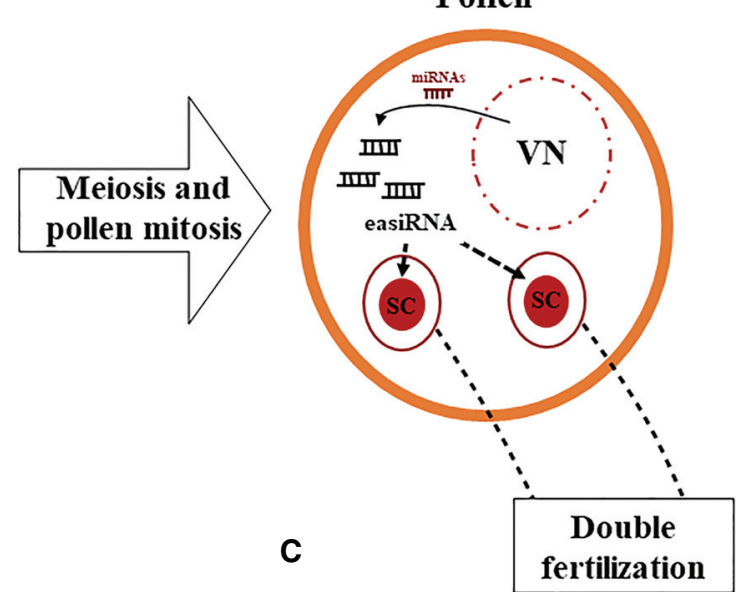
Figure 1. Small RNA movement and influence in plant reproduction. (A) In meiocytes and/or microspores, Pol IV produces small RNA
from activated transposable elements through the different DCL proteins. These molecules influence the transcriptional state of different genes including some involved in pollen development. Pollen-specific miRNA molecules like miR845b in Arabidopsis that are presumably synthesized at meiosis or before and contribute to easiRNA production. $(B)$ In mature pollen, the sperm cells (SC) are mostly inactive but receive epigenetic information in the form of easiRNA molecules produced in the vegetative nucleus (VN). These molecules are again dependent on Pol IV but also miRNA targeting transposon RNA molecules. $(C)$ At fertilization, the two sperm cells fuse with the egg cell (EC) and central cell (CC) of the ovule delivering the haploid paternal genome and potentially the small RNA complement previously loaded into the sperm cells. $(D)$ In the endosperm nuclei of the developing seed, imprinted alleles with specific epigenetic marks are treated differently by the transcriptional machinery. Depicted is a model of a paternally expressed gene where the maternal alleles have been silenced by the PRC2 complex. The maternal silencing is, however, incapable of reaching the paternal that is protected by the epigenetic state conferred by small RNA targeting working with yet unidentified factors.

directed DNA methylation (RdDM) (Matzke and Mosher 2014; Borges and Martienssen 2015; Matzke et al. 2015). CG and CHG methylation are symmetric on both strands and can be maintained during DNA replication by chromatin remodeling and histone modification, but $\mathrm{mCHH}$ is asymmetric and requires RdDM (Law and Jacobsen 2010; Borges and Martienssen 2015). Although high levels of $\mathrm{mCG}$ are found in male meiocytes, microspores, and differentiated sperm nuclei in the pollen, $\mathrm{mCHH}$ is almost completely erased in the male germline (Calarco et al. 2012; Ibarra et al. 2012; Walker et al. 2018), only to be restored to high levels in the mature embryo (An et al. 2017; Bouyer et al. 2017; Kawakatsu et al. 2017). The role of easiRNA during this form of reprogramming is still poorly understood, but might contribute to the restoration of $\mathrm{CHH}$ methylation during embryogenesis. In C. rubella, it was shown that Pol IV is essential for pollen development (Wang et al. 2020). The lack of severe phenotype in Arabidopsis Pol IV mutants may be due to a lower content of active transposons, although fertile Pol IV mutants in maize suggest that other mechanisms may be involved. In maize, Pol IV is required for paramutation, a classical epigenetic phenomenon in which epigenetic marks can be acquired from another allele and maintained in following generations (Hollick 2017). How those epialleles are formed and how they acquire the ability to be propagated through cell divisions remains a tantalizing mystery, as DNA methylation seems to play only a minor role. It has, however, been shown in Arabidopsis that some components of small RNA pathways are both required and sufficient to initiate de novo silencing of naive alleles (Fultz and Slotkin 2017; Gallego-Bartolomé et al. 2019).

Small RNA-loaded AGO4 (and likely its homologs AGO6 and AGO9 in the case of A. thaliana) is recruited to chromatin via noncoding RNA scaffolds produced by another plant-specific DNA-dependent RNA Polymerase, Pol V. Target recognition triggers the slicing of the RNA molecule (Liu et al. 2018) and subsequently, recruitment of factors such as INVOLVED IN DE NOVO METHYLATION2 (IDN2) (Böhmdorfer et al. 2014). IDN2 binds to long (10- to 11-nt) 5 ' overhangs, presumably reflecting the cleaved RNA molecule still bound to the small RNA, and 
in turn recruits a variety of chromatin remodeling proteins responsible for silencing (Zhu et al. 2013; Liu et al. 2016), including DOMAINS REARRANGED METHYLTRANSFERASE2 (DRM2) that methylates corresponding DNA in all sequence contexts (Böhmdorfer et al. 2014). Such methylation is thought to be recognized by members of the SU(VAR)3-9 HOMOLOG (SUVH) through their SRA methylated DNA-binding domains (Du et al. 2014) that can then establish H3K9 methylation in the case of SUVH4, 5, and 6 (Stroud et al. 2014) or propagate DNA methylation by recruiting additional Pol $\mathrm{V}$, in the case of SUVH2 and 9 (Johnson et al. 2014). In doing so, the RdDM pathway perpetuates an environment that is refractory to Pol II transcription thereby keeping TEs silent.

Pol IV mutations lead to genome-wide depletion of 24nt sRNAs (Zhou et al. 2018), but CHH methylation is only lost at a subset of those targets. The difference between the small RNA-dependent and-independent effects on asymmetric DNA methylation levels appears to be related to the presence or absence of Pol V at the locus (Wierzbicki et al. 2012). Indeed, the precise extent of the regions silenced by sRNAs appears to be dictated solely by the activity of Pol V (Böhmdorfer et al. 2016; Liu et al. 2018). It has been proposed that Pol $\mathrm{V}$ recruitment is guided by epigenetic marks like $\mathrm{mC}$ and $\mathrm{H} 3 \mathrm{~K} 9 \mathrm{me} 2$, but the correlation is far from perfect (Böhmdorfer et al. 2016). Importantly, if it simply relies on preexisting marks, Pol V recruitment could not account for de novo establishment of silencing. Recruitment of Pol V is conditioned by the presence of members of the DDR (DEFECTIVE IN RNA-DIRECTED DNA METHYLATION1 (DRD1), DEFECTIVE IN MERISTEM SILENCING3 (DMS3), and RNA-DIRECTED DNA METHYLATION1 (RDM1)) complex (Zhong et al. 2012) whose partial structure has recently come to light (Wongpalee et al. 2019). Interestingly, the targeting of either DMS3 or RDM1 to a naive locus with a zinc finger is sufficient to trigger strong de novo silencing, but only in the presence of Pol V (Gallego-Bartolomé et al. 2019), consistent with an early recruiting role. Moreover, RDM1 has the capacity to bind to DNA (Gao et al. 2010), and DRD1 is the only protein associated with Pol V that has ATPase activity and chromatin remodeling potential for transcription (Wongpalee et al. 2019) as do other Rad54 homologs (Amitani et al. 2006). All in all, the activity of the DDR complex appears as a key to small RNA-guided epigenetic silencing.

\section{FUNCTIONAL ROLE OF SMALL RNA IN THE GERMLINE}

In Arabidopsis, the RdDM pathway targets mostly small repeats, the long terminal repeats of retrotransposons and certain families of DNA transposons (Matzke et al. 2015). Interestingly, these targets are distributed not only in pericentromeric regions where these elements are most abundant, but also in intergenic regions along the chromosome arms in Arabidopsis, tomato, and maize (Gouil and Baulcombe 2016). The proximity between these targeted regions and neighboring genes, therefore, creates the opportunity for sRNAs to influence their transcriptional activity. This type of control is observed in the seed where small RNA-directed epigenetic silencing activity is more pronounced (An et al. 2017; Bouyer et al. 2017; Kawakatsu et al. 2017). Imprinted genes, or alleles differentially expressed in the endosperm depending on the parent of origin are a striking example of such control. The maternally expressed imprinted genes $F W A, S D C$, MOP9.5, DOG1-LIKE 4 (DOGL4), and ALLANTOINASE $(A L N)$ were all shown to be methylated in the endosperm on the paternal side, and this was dependent on sRNA targeting a repeated element found in the promoter (Fig. 1D) (Vu et al. 2013; Zhu et al. 2018; Iwasaki et al. 2019). Interestingly, DOGL4 and $A L N$ are involved in seed dormancy, thereby linking sRNA pathways to this agriculturally important trait. Similar examples of small RNAs regulating imprinted gene expression on the maternal side have also been shown to influence seed development and ultimately seed size (Kirkbride et al. 2019).

It is clear that sRNAs target transcriptionally active regions to silence them, but several questions remain as to how this mechanism is scaled up to hundreds or thousands of genes that must be expressed or silenced in a coordinated fashion (Chuong et al. 2017). This invokes the genetic concept of "balance" to explain phenotypic variation associated with genome dosage (Birchler and Veitia 2007). Early studies of distinctive phenotypes dependent on the dosage of parental chromosomes in plants and flies trace back to the 1920s (Blakeslee et al. 1920; Belling and Blakeslee 1923; Bridges 1925). A few years later in maize, McClintock also reported the spontaneous appearance of "a triploid individual notably more vigorous than its diploid sibs" (McClintock 1929). Albert Blakeslee, working at Cold Spring Harbor Laboratory, first reported the inability to hybridize closely related species or parents with different ploidy, which is often associated with failure in endosperm function and seed collapse. For example, interploidy hybridizations with paternal excess result in endosperm overproliferation and seed abortion, sometimes known as the "triploid block" (Köhler et al. 2010). sRNAs and TEs were recently implicated in the triploid block response in Arabidopsis, as the loss of miR845 and Pol IV-dependent easiRNA in diploid pollen restored viability of triploid seeds almost completely (Erdmann et al. 2017; Borges et al. 2018; Martinez et al. 2018). Strikingly, this is highly reminiscent of hybrid dysgenesis in Drosophila, although in this case piRNAs protect the hybrid (Malone et al. 2015; Martienssen 2010). Thus, plants and animals use similar small RNA guides to control transposon activity and dosage in hybrid genomes.

The triploid block response led to the endosperm balance number (EBN) hypothesis, which was developed in the early 1980 s in potato and then extended to many other crop species, to explain the ratio between maternal and paternal chromosomes via genetic factors required for development of a normal seed (Johnston and Hanneman 1982; Ehlenfeldt and Hanneman 1984; Carputo et al. 1997, 1999). We can now propose that such genetic factors may include small RNA loci, imprinted genes, and TEs 
that were found up-regulated in abortive interploid and interspecific hybrid seeds (Josefsson et al. 2006; Lu et al. 2012; Stoute et al. 2012; Kirkbride et al. 2015; Florez-Rueda et al. 2016; Roth et al. 2018). This includes maternally expressed genes (MEGs) that encode important components of the Polycomb repressor complex (PRC2), such as MEDEA and FERTILIZATION-INDEPENDENT SEED2 (FIS2), that silence the paternal alleles via deposition of H3K27me3 (Lafon-Placette and Köhler 2015; Satyaki and Gehring 2017). Small RNAs and the RdDM pathway are also required for genomic imprinting (Vu et al. 2013; Erdmann et al. 2017; Zhu et al. 2018; Iwasaki et al. 2019; Kirkbride et al. 2019), whereas mutations in PRC2 result in endosperm defects closely resembling the triploid block. These observations lend support to the old idea that endosperm failure in interploidy crosses results from disruption of genomic imprinting (Köhler et al. 2010). Indeed, previous studies in Arabidopsis have shown that loss-of-function mutations in PEGs are able to suppress the triploid block, allowing the formation of viable triploid seeds (Kradolfer et al. 2013; Wolff et al. 2015). Taken together, current models propose that paternally inherited easiRNAs mediate "endosperm balance" by targeting TEs flanking imprinted genes, thus regulating their expression this way. For instance, if MEGs are direct targets of easiRNA regulation, this could result in PRC2 depletion and up-regulation of PEGs. However, there is still no clear evidence that PRC2 activity is impaired in abortive triploid seeds. On the other hand, targeting TEs flanking PEGs could result in their direct up-regulation in a dosage-dependent manner (Martinez et al. 2018), though target loci involved in this response have not been identified either.

Although defects in the RdDM pathway typically have a minor impact on somatic phenotypes in Arabidopsis (Sasaki et al. 2012), mutants losing both 24-nt siRNA and maintenance of DNA and histone methylation show various developmental phenotypes because of the misregulation of imprinted genes (Zemach et al. 2013). For example, $S D C$, an imprinted gene normally expressed maternally in endosperm cells, is up-regulated during the somatic developmental stage in that context, resulting in curly leaf and short stature phenotypes (Henderson and Jacobsen 2008; Zemach et al. 2013). In addition, reduced fertility and floral defects are also observed in the mutant defective in DDM1 and RDR6-dependent 21-nt and 22-nt sRNAs (Creasey et al. 2014), suggesting an important role of epigenetically activated 21-nt and 22-nt sRNAs. These defects are more severe when 24-nt siRNA is further depleted (Sasaki et al. 2012), and triple mutants suffer from chromosome missegregation (A Shimada and RA Martienssen, unpubl. data), reminiscent of the regulation of chromosome segregation by RNA interference in Schizosaccharomyces pombe (Gutbrod and Martienssen 2020). Thus in somatic tissues, sRNA molecules cooperatively work as a backup system for DNA methylation to maintain plant fitness and chromosome integrity.

It is revealing that the $\mathrm{RdDM}$ pathway is only found intact in the angiosperms-flowering plants (Lee et al. 2011; Huang et al. 2015). For example, key factors appear to be absent or incomplete in the gymnosperm Norway spruce, Pices abies (Ma et al. 2015; Matzke et al. 2015; Ausin et al. 2016; Pei et al. 2019). It is tempting to speculate that RdDM evolved with the appearance of double fertilization and genomic imprinting in the endosperm of flowering plants, a tissue that has no equivalent in gymnosperms. It has been speculated that this pathway evolved as a facilitator of polyploidization, which has had a crucial role in the evolution of angiosperms (Matzke et al. 2015), but is relatively rare in gymnosperms (IckertBond et al. 2020). This is also consistent with a key role for sRNA in mediating genome dosage responses during interploidy hybridization barriers in the endosperm (Erdmann et al. 2017; Borges et al. 2018; Martinez et al. 2018; Moreno-Romero et al. 2019; Satyaki and Gehring 2019). sRNA molecules may indeed target all the different copies of a given TE and mark them with DNA methylation, insuring their transcriptional control and potentially accelerating their decay and elimination. In line with this hypothesis, it appears that concerted changes in sRNA abundance and epigenetic changes occur mostly at transposons in autotetraploid rice (Zhang et al. 2015) and in rapeseed following whole genome duplication (Cheng et al. 2016). There is also evidence of a transient increase in sRNA levels in newly synthesized allopolyploid Brassica napus (Martinez Palacios et al. 2019), whereas $\mathrm{CHH}$ methylation levels at TEs flanking genes are anticorrelated with their expression and may, therefore, be related to the establishment of subgenome dominance in interspecies crosses (Edger et al. 2017). All this points to an active role for sRNAs in unexpected "genomic shocks" that occur when distantly related genomes meet (McClintock 1984).

\section{CONCLUSION}

Since their discovery, sRNAs have been implicated in a plethora of biological processes ranging from gene regulation to defense against invaders. Among these important functions, their ability to be inherited by the next generation and influence it remains one of the most intriguing. Flowering plants present a fantastic opportunity to study such phenomenon because of their propensity to transmit epigenetic information to their offspring. The knowledge gained is already being applied to address emerging agricultural and environmental challenges.

\section{ACKNOWLEDGMENTS}

The authors thank Claudia Köhler, Daniel Grimanelli, and members of the Martienssen laboratory for fruitful discussions. This research was supported by the Howard Hughes Medical Institute and by grants from the National Science Foundation Plant Genome Research Program to R.A.M.

\section{REFERENCES}

Amitani I, Baskin RJ, Kowalczykowski SC. 2006. Visualization of Rad54, a chromatin remodeling protein, translocating on 
single DNA molecules. Mol Cell 23: 143-148. doi:10.1016/j .molcel.2006.05.009

An YC, Goettel W, Han Q, Bartels A, Liu Z, Xiao W. 2017. Dynamic changes of genome-wide DNA methylation during soybean seed development. Sci Rep 7: 12263. doi:10.1038/ s41598-017-12510-4

Ausin I, Feng S, Yu C, Liu W, Kuo HY, Jacobsen EL, Zhai J, Gallego-Bartolome J, Wang L, Egertsdotter U, et al. 2016. DNA methylome of the 20-gigabase Norway spruce genome. Proc Natl Acad Sci 113: E8106-E8113. doi:10.1073/pnas .1618019113

Belling J, Blakeslee AF. 1923. The reduction division in haploid, diploid, triploid and tetraploid Daturas. Proc Natl Acad Sci 9: 106-111. doi:10.1073/pnas.9.4.106

Birchler JA, Veitia RA. 2007. The gene balance hypothesis: from classical genetics to modern genomics. Plant Cell 19: 395402. doi:10.1105/tpc. 106.049338

Blakeslee AF, Belling J, Farnham ME. 1920. Chromosomal duplication and Mendelian phenomena in Datura mutants. Science 52: 388-390. doi:10.1126/science.52.1347.388

Blevins T, Podicheti R, Mishra V, Marasco M, Wang J, Rusch D, Tang H, Pikaard CS. 2015. Identification of Pol IV and RDR2dependent precursors of $24 \mathrm{nt}$ siRNAs guiding de novo DNA methylation in Arabidopsis. elife 4: e09591. doi:10.7554/ eLife.09591

Böhmdorfer G, Rowley MJ, Kucinski J, Zhu Y, Amies I, Wierzbicki AT. 2014. RNA-directed DNA methylation requires stepwise binding of silencing factors to long non-coding RNA. Plant J 79: 181-191. doi:10.1111/tpj.12563

Böhmdorfer G, Sethuraman S, Rowley MJ, Krzyszton M, Rothi MH, Bouzit L, Wierzbicki AT. 2016. Long non-coding RNA produced by RNA polymerase $\mathrm{V}$ determines boundaries of heterochromatin. eLife 5: e19092. doi:10.7554/eLife.19092

Borges F, Martienssen RA. 2015. The expanding world of small RNAs in plants. Nat Rev Mol Cell Biol 16: 727-741. doi:10 $.1038 / \mathrm{nrm} 4085$

Borges F, Parent J-S, van Ex F, Wolff P, Martínez G, Köhler C, Martienssen RA. 2018. Transposon-derived small RNAs triggered by miR 845 mediate genome dosage response in Arabidopsis. Nat Genet 50: 186-192. doi:10.1038/s41588-0170032-5

Bouyer D, Kramdi A, Kassam M, Heese M, Schnittger A, Roudier F, Colot V. 2017. DNA methylation dynamics during early plant life. Genome Biol 18: 179. doi:10.1186/s13059-0171313-0

Bridges CB. 1925. Sex in relation to chromosomes and genes. Am Soc Nat 59: 127-137. doi:10.1086/280023

Calarco JP, Borges F, Donoghue MTA, Van Ex F, Jullien PE, Lopes T, Gardner R, Berger F, Feijó JA, Becker JD, et al. 2012. Reprogramming of DNA methylation in pollen guides epigenetic inheritance via small RNA. Cell 151: 194-205. doi:10.1016/j.cell.2012.09.001

Carputo D, Barone A, Cardi T, Sebastiano A, Frusciante L, Peloquin SJ. 1997. Endosperm balance number manipulation for direct in vivo germplasm introgression to potato from a sexually isolated relative (Solanum commersonii Dun). Proc Natl Acad Sci 94: 12013-12017. doi:10.1073/pnas.94.22.12013

Carputo D, Monti L, Werner JE, Frusciante L. 1999. Uses and usefulness of endosperm balance number. Theor Appl Genet 98: 478-484. doi:10.1007/s001220051095

Chandler VL. 2010. Paramutation's properties and puzzles. Science 330: 628-629. doi:10.1126/science.1191044

Cheng F, Sun C, Wu J, Schnable J, Woodhouse MR, Liang J, Cai C, Freeling M, Wang X. 2016. Epigenetic regulation of subgenome dominance following whole genome triplication in Brassica rapa. New Phytol 211: 288-299. doi:10.1111/nph .13884

Chuong EB, Elde NC, Feschotte C. 2017. Regulatory activities of transposable elements: from conflicts to benefits. Nat Rev Genet 18: $71-86$. doi:10.1038/nrg.2016.139

Coe EH. 1966. The properties, origin, and mechanism of conversion-type inheritance at the B locus in maize. Genetics 53: 1035-1063.
Corem S, Doron-Faigenboim A, Jouffroy O, Maumus F, Arazi T, Bouché N. 2018. Redistribution of $\mathrm{CHH}$ methylation and small interfering RNAs across the genome of tomato $d d m 1$ mutants. Plant Cell 30: 1628-1644. doi:10.1105/tpc.18.00167

Creasey KM, Zhai J, Borges F, Van Ex F, Regulski M, Meyers BC, Martienssen RA. 2014. miRNAs trigger widespread epigenetically activated siRNAs from transposons in Arabidopsis. Nature 508: 411-415. doi:10.1038/nature13069

Du J, Johnson LM, Groth M, Feng S, Hale CJ, Li S, Vashisht AA, Gallego-Bartolome J, Wohlschlegel JA, Patel DJ, et al. 2014. Mechanism of DNA methylation-directed histone methylation by KRYPTONITE. Mol Cell 55: 495-504. doi:10.1016/j .molcel.2014.06.009

Edger PP, Smith R, McKain MR, Cooley AM, Vallejo-Marin M, Yuan Y, Bewick AJ, Ji L, Platts AE, Bowman MJ, et al. 2017. Subgenome dominance in an interspecific hybrid, synthetic allopolyploid, and a 140-year-old naturally established neoallopolyploid monkeyflower. Plant Cell 29: 2150-2167. doi:10.1105/tpc. 17.00010

Ehlenfeldt MK, Hanneman RE. 1984. The use of Endosperm Balance Number and $2 \mathrm{n}$ gametes to transfer exotic germplasm in potato. Theor Appl Genet 68: 155-161. doi:10.1007/ BF00252332

Erdmann RM, Satyaki PR V, Klosinska M, Gehring M. 2017. A small RNA pathway mediates global allelic dosage in endosperm. Cell Rep 21: 3364-3372. doi:10.1016/j.celrep .2017.11.078

Florez-Rueda AM, Paris M, Schmidt A, Widmer A, Grossniklaus $\mathrm{U}$, Städler T. 2016. Genomic imprinting in the endosperm is systematically perturbed in abortive hybrid tomato seeds. $\mathrm{Mol}$ Biol Evol 33: 2935-2946. doi:10.1093/molbev/msw175

Fu F-F, Dawe RK, Gent JI. 2018. Loss of RNA-directed DNA methylation in maize chromomethylase and DDM1-type nucleosome remodeler mutants. Plant Cell 30: 1617-1627. doi:10.1105/tpc. 18.00053

Fultz D, Slotkin RK. 2017. Exogenous transposable elements circumvent identity-based silencing, permitting the dissection of expression-dependent silencing. Plant Cell 29: 360-376. doi:10.1105/tpc.16.00718

Gallego-Bartolomé J, Liu W, Kuo PH, Feng S, Ghoshal B, Gardiner J, Zhao JMC, Park SY, Chory J, Jacobsen SE. 2019. Cotargeting RNA polymerases IV and V promotes efficient de novo DNA methylation in Arabidopsis. Cell 176: 1068-1082. e19. doi:10.1016/j.cell.2019.01.029

Gao Z, Liu H-L, Daxinger L, Pontes O, He X, Qian W, Lin H, Xie M, Lorkovic ZJ, Zhang S, et al. 2010. An RNA polymerase IIand AGO4-associated protein acts in RNA-directed DNA methylation. Nature 465: 106-109. doi:10.1038/nature09025

Gouil Q, Baulcombe DC. 2016. DNA methylation signatures of the plant chromomethyltransferases. PLOS Genet 12: e1006526. doi:10.1371/journal.pgen.1006526

Gutbrod MJ, Martienssen RA. 2020. Conserved chromosomal functions of RNA interference. Nat Rev Genet 21: 311-331. doi:10.1038/s41576-019-0203-6

Heard E, Martienssen RA. 2014. Transgenerational epigenetic inheritance: myths and mechanisms. Cell 157: 95-109. doi:10.1016/j.cell.2014.02.045

Henderson IR, Jacobsen SE. 2008. Tandem repeats upstream of the Arabidopsis endogene SDC recruit non-CG DNA methylation and initiate siRNA spreading. Genes Dev 22: 15971606. doi:10.1101/gad.1667808

Hollick JB. 2017. Paramutation and related phenomena in diverse species. Nat Rev Genet 18: 5-23. doi:10.1038/nrg .2016 .115

Huang Y, Kendall T, Forsythe ES, Dorantes-Acosta A, Li S, Caballero-Pérez J, Chen X, Arteaga-Vázquez M, Beilstein MA, Mosher RA. 2015. Ancient origin and recent innovations of RNA polymerase IV and V. Mol Biol Evol 32: 1788-1799. doi:10.1093/molbev/msv060

Ibarra CA, Feng X, Schoft VK, Hsieh T-F, Uzawa R, Rodrigues JA, Zemach A, Chumak N, Machlicova A, Nishimura T, et al. 2012. Active DNA demethylation in plant companion cells 
reinforces transposon methylation in gametes. Science 337: 1360-1364. doi:10.1126/science.1224839

Ickert-Bond SM, Sousa A, Min Y, Loera I, Metzgar J, Pellicer J, Hidalgo O, Leitch IJ. 2020. Polyploidy in gymnospermsinsights into the genomic and evolutionary consequences of polyploidy in Ephedra. Mol Phylogenet Evol 147: 106786. doi:10.1016/j.ympev.2020.106786

Ingouff M, Selles B, Michaud C, Vu TM, Berger F, Schorn AJ, Autran D, Van Durme M, Nowack MK, Martienssen RA, et al. 2017. Live-cell analysis of DNA methylation during sexual reproduction in Arabidopsis reveals context and sex-specific dynamics controlled by noncanonical RdDM. Genes Dev 31: 72-83. doi:10.1101/gad.289397.116

Iwasaki M, Hyvärinen L, Piskurewicz U, Lopez-Molina L. 2019. Non-canonical RNA-directed DNA methylation participates in maternal and environmental control of seed dormancy. eLife 8: e37434. doi:10.7554/eLife.37434

Johnson LM, Du J, Hale CJ, Bischof S, Feng S, Chodavarapu RK, Zhong X, Marson G, Pellegrini M, Segal DJ, et al. 2014. SRA- and SET-domain-containing proteins link RNA polymerase V occupancy to DNA methylation. Nature 507: 124 128. doi:10.1038/nature12931

Johnston SA, Hanneman RE. 1982. Manipulations of endosperm balance number overcome crossing barriers between diploid Solanum species. Science 217: 446-448. doi:10.1126/science .217.4558.446

Josefsson C, Dilkes B, Comai L. 2006. Parent-dependent loss of gene silencing during interspecies hybridization. Curr Biol 16: 1322-1328. doi:10.1016/j.cub.2006.05.045

Kawakatsu T, Nery JR, Castanon R, Ecker JR. 2017. Dynamic DNA methylation reconfiguration during seed development and germination. Genome Biol 18: 171. doi:10.1186/s13059017-1251-x

Kermicle JL. 1970. Dependence of the $R$-mottled aleurone phenotype in maize on mode of sexual transmission. Genetics 66: 69-85.

Kirkbride RC, Yu HH, Nah G, Zhang C, Shi X, Chen ZJ. 2015. An epigenetic role for disrupted paternal gene expression in postzygotic seed abortion in Arabidopsis interspecific hybrids. Mol Plant 8: 1766-1775. doi:10.1016/j.molp.2015.09.009

Kirkbride RC, Lu J, Zhang C, Mosher RA, Baulcombe DC. 2019. Maternal small RNAs mediate spatial-temporal regulation of gene expression, imprinting, and seed development in Arabidopsis. Proc Natl Acad Sci 116: 2761-2766. doi:10 $.1073 /$ pnas. 1807621116

Köhler C, Mittelsten Scheid O, Erilova A. 2010. The impact of the triploid block on the origin and evolution of polyploid plants. Trends Genet 26: 142-148. doi:10.1016/j.tig .2009.12.006

Kradolfer D, Wolff P, Jiang H, Siretskiy A, Köhler C. 2013. An imprinted gene underlies postzygotic reproductive isolation in Arabidopsis thaliana. Dev Cell 26: 525-535. doi:10.1016/j .devcel.2013.08.006

Lafon-Placette C, Köhler C. 2015. Epigenetic mechanisms of postzygotic reproductive isolation in plants. Curr Opin Plant Biol 23: 39-44. doi:10.1016/j.pbi.2014.10.006

Law JA, Jacobsen SE. 2010. Establishing, maintaining and modifying DNA methylation patterns in plants and animals. Nat Rev Genet 11: 204-220. doi:10.1038/nrg2719

Law JA, Du J, Hale CJ, Feng S, Krajewski K, Palanca AMS, Strahl BD, Patel DJ, Jacobsen SE. 2013. Polymerase IV occupancy at RNA-directed DNA methylation sites requires SHH1. Nature 498: 385-389. doi:10.1038/nature12178

Lee EK, Cibrian-Jaramillo A, Kolokotronis SO, Katari MS, Stamatakis A, Ott M, Chiu JC, Little DP, Stevenson DW, McCombie WR, et al. 2011. A functional phylogenomic view of the seed plants. PLoS Genet 7: e1002411. doi:10.1371/journal .pgen.1002411

Liu Z-W, Zhou J-X, Huang H-W, Li Y-Q, Shao C-R, Li L, Cai T, Chen S, He X-J. 2016. Two components of the RNA-directed DNA methylation pathway associate with MORC6 and silence loci targeted by MORC6 in Arabidopsis. PLOS Genet 12: e1006026. doi:10.1371/journal.pgen.1006026
Liu W, Duttke SH, Hetzel J, Groth M, Feng S, Gallego-Bartolome J, Zhong Z, Kuo HY, Wang Z, Zhai J, et al. 2018. RNAdirected DNA methylation involves co-transcriptional small-RNA-guided slicing of polymerase $\mathrm{V}$ transcripts in Arabidopsis. Nat Plants 4: 181-188. doi:10.1038/s41477017-0100-y

Lu J, Zhang C, Baulcombe DC, Chen ZJ. 2012. Maternal siRNAs as regulators of parental genome imbalance and gene expression in endosperm of Arabidopsis seeds. Proc Natl Acad Sci 109: 5529-5534. doi:10.1073/pnas. 1203094109

Ma L, Hatlen A, Kelly LJ, Becher H, Wang W, Kovarik A, Leitch IJ, Leitch AR. 2015. Angiosperms are unique among land plant lineages in the occurrence of key genes in the RNAdirected DNA methylation (RdDM) Pathway. Genome Biol Evol 7: 2648-2662. doi:10.1093/gbe/evv171

Malone CD, Lehmann R, Teixeira FK. 2015. The cellular basis of hybrid dysgenesis and Stellate regulation in Drosophila. Curr Opin Genet Dev 34: 88-94. doi:10.1016/j.gde.2015.09.003

Martienssen RA. 2010. Heterochromatin, small RNA and postfertilization dysgenesis in allopolyploid and interploid hybrids of Arabidopsis. New Phytol 186: 46-53. doi:10.1111/j.14698137.2010.03193.x

Martínez G, Panda K, Köhler C, Slotkin RK. 2016. Silencing in sperm cells is directed by RNA movement from the surrounding nurse cell. Nat Plants 2: 16030. doi:10.1038/nplants .2016 .30

Martinez G, Wolff P, Wang Z, Moreno-Romero J, Santos-González J, Conze LL, DeFraia C, Slotkin K, Köhler C. 2018. Paternal easiRNAs regulate parental genome dosage in Arabidopsis. Nat Genet 50: 193-198. doi:10.1038/s41588-0170033-4

Martinez Palacios P, Jacquemot MP, Tapie M, Rousselet A, Diop M, Remoue C, Falque M, Lloyd A, Jenczewski E, Lassalle G, et al. 2019. Assessing the response of small RNA populations to allopolyploidy using resynthesized Brassica napus allotetraploids. Mol Biol Evol 36: 709-726. doi:10.1093/molbev/ msz007

Matzke MA, Mosher RA. 2014. RNA-directed DNA methylation: an epigenetic pathway of increasing complexity. Nat Rev Genet 15: 394-408. doi:10.1038/nrg3683

Matzke MA, Kanno T, Matzke AJM. 2015. RNA-directed DNA methylation: the evolution of a complex epigenetic pathway in flowering plants. Annu Rev Plant Biol 66: 243-267. doi:10 .1146/annurev-arplant-043014-114633

McClintock B. 1929. A cytological and genetical study of triploid maize. Genetics 14: 180-222.

McClintock B. 1961. Some parallels between gene control systems in maize and in bacteria. Am Nat 95: 265-277. doi:10 $.1086 / 282188$

McClintock B. 1984. The significance of responses of the genome to challenge. Science 226: 792-801. doi:10.1126/sci ence. 15739260

Mohn F, Sienski G, Handler D, Brennecke J. 2014. The RhinoDeadlock-Cutoff complex licenses noncanonical transcription of dual-strand piRNA clusters in Drosophila. Cell 157: 1364 1379. doi:10.1016/j.cell.2014.04.031

Moreno-Romero J, Del Toro-De León G, Yadav VK, SantosGonzález J, Köhler C. 2019. Epigenetic signatures associated with imprinted paternally-expressed genes in the Arabidopsis endosperm. Genome Biol 20: 41. doi:10.1186/s13059-0191652-0

Nuthikattu S, McCue AD, Panda K, Fultz D, DeFraia C, Thomas EN, Slotkin RK. 2013. The initiation of epigenetic silencing of active transposable elements is triggered by RDR6 and 21-22 nucleotide small interfering RNAs. Plant Physiol 162: 116131. doi:10.1104/pp.113.216481

Ong-Abdullah M, Ordway JM, Jiang N, Ooi S-E, Kok S-Y, Sarpan N, Azimi N, Hashim AT, Ishak Z, Rosli SK, et al. 2015. Loss of Karma transposon methylation underlies the mantled somaclonal variant of oil palm. Nature 525: 533-537. doi:10 $.1038 /$ nature 15365

Panda K, Ji L, Neumann DA, Daron J, Schmitz RJ, Slotkin RK. 2016. Full-length autonomous transposable elements are pref- 
erentially targeted by expression-dependent forms of RNAdirected DNA methylation. Genome Biol 17: 170. doi:10 .1186/s13059-016-1032-y

Pei L, Zhang L, Li J, Shen C, Qiu P, Tu L, Zhang X, Wang M. 2019. Tracing the origin and evolution history of methylationrelated genes in plants. BMC Plant Biol 19: 1-13. doi:10.1186/ s12870-019-1923-7

Pumplin N, Sarazin A, Jullien PE, Bologna NG, Oberlin S, Voinnet O. 2016. DNA methylation influences the expression of DICER-LIKE4 isoforms, which encode proteins of alternative localization and function. Plant Cell 28: 2786-2804. doi:10 $.1105 /$ tpc. 16.00554

Roth M, Florez-Rueda AM, Paris M, Städler T. 2018. Wild tomato endosperm transcriptomes reveal common roles of genomic imprinting in both nuclear and cellular endosperm. Plant $J$ 95: 1084-1101. doi:10.1111/tpj.14012

Sasaki T, Kobayashi A, Saze H, Kakutani T. 2012. RNAi-independent de novo DNA methylation revealed in Arabidopsis mutants of chromatin remodeling gene DDM1. Plant $J$ 70: 750-758. doi:10.1111/j.1365-313X.2012.04911.x

Satyaki PRV, Gehring M. 2017. DNA methylation and imprinting in plants: machinery and mechanisms. Crit Rev Biochem Mol Biol 52: 163-175. doi:10.1080/10409238.2017.1279119

Satyaki PRV, Gehring M. 2019. Paternally acting canonical RNA-directed DNA methylation pathway genes sensitize Arabidopsis endosperm to paternal genome dosage. Plant Cell 31: 1563-1578. doi: $10.1105 /$ tpc. 19.00047

Schorn AJ, Gutbrod MJ, LeBlanc C, Martienssen R. 2017. LTRretrotransposon control by tRNA-derived small RNAs. Cell 170: 61-71.e11. doi:10.1016/j.cell.2017.06.013

Singh J, Mishra V, Wang F, Huang H-Y, Pikaard CS. 2019. Reaction mechanisms of Pol IV, RDR2, and DCL3 drive RNA channeling in the siRNA-directed DNA methylation pathway. Mol Cell 75: 576-589.e5. doi:10.1016/j.molcel.2019.07.008

Slotkin RK, Vaughn M, Borges F, Tanurdžić M, Becker JD, Feijó JA, Martienssen RA. 2009. Epigenetic reprogramming and small RNA silencing of transposable elements in pollen. Cell 136: 461-472. doi:10.1016/j.cell.2008.12.038

Stoute AI, Varenko V, King GJ, Scott RJ, Kurup S. 2012. Parental genome imbalance in Brassica oleracea causes asymmetric triploid block. Plant $J$ 71: 503-516. doi:10.1111/j.1365313X.2012.05015.x

Stroud H, Do T, Du J, Zhong X, Feng S, Johnson L, Patel DJ, Jacobsen SE. 2014. Non-CG methylation patterns shape the epigenetic landscape in Arabidopsis. Nat Struct Mol Biol 21: 64-72. doi:10.1038/nsmb.2735

Šurbanovski N, Brilli M, Moser M, Si-Ammour A. 2016. A highly specific microRNA-mediated mechanism silences LTR retrotransposons of strawberry. Plant $J$ 85: 70-82. doi:10.1111/tpj.13090

Swarts DC, Makarova K, Wang Y, Nakanishi K, Ketting RF, Koonin E V, Patel DJ, van der Oost J. 2014. The evolutionary journey of Argonaute proteins. Nat Struct Mol Biol 21: 743753. doi: $10.1038 /$ nsmb. 2879

Teixeira FK, Colot V. 2010. Repeat elements and the Arabidopsis DNA methylation landscape. Heredity (Edinb) 105: 14-23. doi:10.1038/hdy.2010.52

Vu TM, Nakamura M, Calarco JP, Susaki D, Lim PQ, Kinoshita T, Higashiyama T, Martienssen RA, Berger F. 2013. RNAdirected DNA methylation regulates parental genomic imprinting at several loci in Arabidopsis. Development 140: 2953-2960. doi:10.1242/dev.092981
Walker J, Gao H, Zhang J, Aldridge B, Vickers M, Higgins JD, Feng X. 2018. Sexual-lineage-specific DNA methylation regulates meiosis in Arabidopsis. Nat Genet 50: 130-137. doi:10 .1038/s41588-017-0008-5

Wang Z, Butel N, Santos-González J, Borges F, Yi J, Martienssen R, Martinez G, Köhler C. 2020. Polymerase IV plays a crucial role in pollen development in Capsella. Plant Cell 32: 950 966 doi:10.1105/tpc.19.00938

Wierzbicki AT, Cocklin R, Mayampurath A, Lister R, Rowley MJ, Gregory BD, Ecker JR, Tang H, Pikaard CS. 2012. Spatial and functional relationships among Pol V-associated loci, Pol IV-dependent siRNAs, and cytosine methylation in the Arabidopsis epigenome. Genes Dev 26: 1825-1836. doi:10.1101/ gad.197772.112

Wolff P, Jiang H, Wang G, Santos-González J, Köhler C. 2015. Paternally expressed imprinted genes establish postzygotic hybridization barriers in Arabidopsis thaliana. eLife 4: e10074. doi:10.7554/eLife.10074

Wongpalee SP, Liu S, Gallego-Bartolomé J, Leitner A, Aebersold R, Liu W, Yen L, Nohales MA, Kuo PH, Vashisht AA, et al. 2019. CryoEM structures of Arabidopsis DDR complexes. Nat Commun 10: 3916. doi:10.1038/s41467-019-11759-9

Yu B, Lin YA, Parhad SS, Jin Z, Ma J, Theurkauf WE, Zhang ZZ, Huang Y. 2018. Structural insights into Rhino-Deadlock complex for germline piRNA cluster specification. EMBO Rep 19: e45418. doi:10.15252/embr.201745418

Zemach A, Kim MY, Hsieh PH, Coleman-Derr D, EshedWilliams L, Thao K, Harmer SL, Zilberman D. 2013. The Arabidopsis nucleosome remodeler DDM1 allows DNA methyltransferases to access H1-containing heterochromatin. Cell 153: 193-205. doi:10.1016/j.cell.2013.02.033

Zhai J, Bischof S, Wang H, Feng S, Lee TF, Teng C, Chen X, Park SY, Liu L, Gallego-Bartolome J, et al. 2015. A one precursor one siRNA model for Pol IV-dependent siRNA biogenesis. Cell 163: 445-455. doi:10.1016/j.cell.2015.09.032

Zhang J, Liu Y, Xia E-H, Yao Q-Y, Liu X-D, Gao L-Z. 2015. Autotetraploid rice methylome analysis reveals methylation variation of transposable elements and their effects on gene expression. Proc Natl Acad Sci 112: E7022-E7029. doi:10 $.1073 /$ pnas. 1515170112

Zhao Y, Wang S, Wu W, Li L, Jiang T, Zheng B. 2018. Clearance of maternal barriers by paternal miR 159 to initiate endosperm nuclear division in Arabidopsis. Nat Commun 9: 5011. doi:10 .1038/s41467-018-07429-x

Zhong X, Hale CJ, Law JA, Johnson LM, Feng S, Tu A, Jacobsen SE. 2012. DDR complex facilitates global association of RNA polymerase $\mathrm{V}$ to promoters and evolutionarily young transposons. Nat Struct Mol Biol 19: 870-875. doi:10.1038/nsmb .2354

Zhou M, Palanca AMS, Law JA. 2018. Locus-specific control of the de novo DNA methylation pathway in Arabidopsis by the CLASSY family. Nat Genet 50: 865-873. doi:10.1038/ s41588-018-0115-y

Zhu Y, Rowley MJ, Böhmdorfer G, Wierzbicki AT. 2013. A SWI/ SNF chromatin-remodeling complex acts in noncoding RNAmediated transcriptional silencing. Mol Cell 49: 298-309. doi:10.1016/j.molcel.2012.11.011

Zhu H, Xie W, Xu D, Miki D, Tang K, Huang C-F, Zhu J-K. 2018. DNA demethylase ROS1 negatively regulates the imprinting of DOGL4 and seed dormancy in Arabidopsis thaliana. Proc Natl Acad Sci 115: E9962-E9970. doi:10.1073/ pnas. 1812847115 


\section{$8_{\text {CSH }}^{\infty}$ \& Cold Spring Harbor Symposia SYMPOSIA on Quantitative Biology}

\section{Small RNA Function in Plants: From Chromatin to the Next Generation}

Jean-Sébastien Parent, Filipe Borges, Atsushi Shimada, et al.

Cold Spring Harb Symp Quant Biol published online June 9, 2020

Access the most recent version at doi:10.1101/sqb.2019.84.040394

$\mathbf{P}<\mathbf{P} \quad$ Published online June 9, 2020 in advance of the print journal.

Creative This article is distributed under the terms of the

Commons http://creativecommons.org/licenses/by/4.0/, which permits unrestricted

License reuse and redistribution provided that the original author and source are credited.

Email Alerting Receive free email alerts when new articles cite this article - sign up in Service the box at the top right corner of the article or click here.

Advance online articles have been peer reviewed and accepted for publication but have not yet appeared in the paper journal (edited, typeset versions may be posted when available prior to final publication). Advance online articles are citable and establish publication priority; they are indexed by PubMed from initial publication. Citations to Advance online articles must include the digital object identifier (DOIs) and date of initial publication.

To subscribe to Cold Spring Harbor Symposia on Quantitative Biology go to: http://symposium.cshlp.org/subscriptions 